\title{
Tris (2-aminoethyl) Amine Functionalized Nanoporous Silica SBA-15 as a Potential Drug Carrier for Citalopram
}

\author{
Fatemeh Dalayi ${ }^{1}$, Leila Hajiaghababaei ${ }^{*}$, Alireza Badiei ${ }^{2}$, Elham Boorboor Azimi ${ }^{2}$, Mohammad Reza Ganjali ${ }^{3}$, \\ Ghodsi Mohammadi Ziarani ${ }^{4}$
}

'Department of Chemistry, Yadegar-e-Imam Khomeini (RAH) Shahre Rey Branch, Islamic Azad University, Tehran, Iran ${ }^{2}$ School of Chemistry, College of Science, University of Tehran, Tehran, Iran

${ }^{3}$ Center of Excellence in Electrochemistry, School of Chemistry, College of Science, University of Tehran, Tehran, Iran

${ }^{4}$ Department of Chemistry, Alzahra University, Tehran, Iran

\author{
*Correspondence to \\ Leila Hajiaghababaei, \\ 1Department of Chemistry, Yadegar- \\ e-Imam Khomeini (RAH) Shahre Rey \\ Branch, Islamic Azad University, \\ Tehran, Iran, \\ Tel: 09125017614, \\ Email: Ihajiaghababaei@yahoo.com
}

Received November 25, 2018 Accepted February 23, 2019 Published online December 31, 2019

\begin{abstract}
Introduction: Ordered nanoporous silica such as SBA-15 has a great potential for application in controlled drug release systems. Chemical modification of the silanol groups of SBA-15 allows better control over drug loading and release. Therefore, tris(2-aminoethyl) amine-functionalized mesoporous silica SBA-15 was evaluated as a potential carrier for the delivery of citalopram. Methods: Tris (2-aminoethyl) amine-functionalized SBA-15 was synthesized and characterized by various methods. Citalopram was loaded on the functionalized SBA-15 and drug release into simulated body fluid (SBF) solution and phosphate buffers was investigated.

Results: The optimal condition for loading of the citalopram was obtained at $\mathrm{pH}=9$ after stirring for 5 minutes. The release profile of citalopram was monitored in phosphate buffers with three different $\mathrm{pH}$ values of 5,7 , and 8 . A faster release rate at lower $\mathrm{pH}$ value was observed, suggesting a weaker interaction because of the protonation of the amino group of the functionalized SBA15. The average release rate of citalopram from each gram of functionalized SBA-15 was $12 \mu \mathrm{g}$ $\mathrm{h}^{-1}$ in the SBF.

Conclusion: The results showed that loading amount and release rate of citalopram depended on $\mathrm{pH}$ value and the release process showed a very slow release pattern. Therefore, tris (2-aminoethyl) amine-functionalized SBA-15 is a suitable carrier for controlled release of citalopram and has a great potential for disease therapy.

Keywords: Tris(2-aminoethyl) amine-functionalized SBA-15, Citalopram, Controlled release, Spectrophotometry.
\end{abstract}

Please cite this article as follows: Dalayi F, Hajiaghababaei L, Badiei A, Boorboor Azimi E, Ganjali MR, Mohammadi Ziarani.G. Tris (2-aminoethyl) Amine Functionalized Nanoporous Silica SBA-15 as a Potential Drug Carrier for Citalopram . Int J Basic Sci Med. 2019;4(4):155162. doi: 10.34172 ijbms.2019.06.

\begin{abstract}
Introduction
Citalopram is an antidepressant of the selective serotonin reuptake inhibitor (SSRI) class. This drug acts by restoring the balance of serotonin in the brain. Some studies proposed that a potential cause for antidepressant effect of citalopram might be its interaction with cannabinoid protein-couplings in the brain of rats. ${ }^{1}$ In 1998, citalopram received the approval of US Food and Drug Administration for treating major depression. ${ }^{2,3}$ In the European countries, citalopram is approved for the treatment of panic disorder, ${ }^{4,5}$ with or without agoraphobia. The dose of citalopram varies from 10 to $40 \mathrm{mg} / \mathrm{d}$ at
\end{abstract}

maximum. ${ }^{6}$ Overdose can cause vomiting, disturbances in heart rhythm, dizziness, sedation, nausea, sweating, tremor, confusion, amnesia, convulsions, and coma. ${ }^{7}$ Overdose of citalopram can cause death when combined with other drugs. Normally, citalopram exists in plasma or blood in the concentrations within the range of $50-400 \mu \mathrm{g} / \mathrm{L}$ in patients receiving the drug therapeutically, $1000-3000 \mu \mathrm{g} / \mathrm{L}$ in people surviving the acute overdose and 3-30 mg/L in not-survived patients. ${ }^{8-10}$ Additionally, it was reported to be the most dangerous SSRI in overdose. ${ }^{11}$

On the other hand, researchers have concentrated on mesoporous silica

(C) 2019 The Author(s); Published by Zabol University of Medical Sciences. This is an open-access article distributed under the terms of the Creative Commons Attribution License (http://creativecommons.org/licenses/by/4.0), which permits unrestricted use, distribution, and reproduction in any medium, provided the original work is properly cited. 
substances due to their potential application in the fields of nanomedicine because of their tailorable surface charge, low cytotoxicity, huge potentials for organic functionalization, and good biocompatibility. Nanomedicine is subdivided into different fields, one of which is drug delivery system. For drug delivery, various material designs have been proposed, mainly based on liposomes, polymers, nanoparticles, and mesoporous silica. Ordered mesoporous silica such as MCM-41, ${ }^{12}$ LUS- $1,{ }^{13,14}$ and SBA- $15^{15}$ can be applied in many fields such as drug delivery, ${ }^{16-18}$ preconcentration of metals, ${ }^{13,14}$ dye removal, ${ }^{15,19}$ and catalysis. ${ }^{12}$ The extended surface area of these materials makes them be highly absorbed and have high pore volume, allowing a large amount of drug to be encapsulated. Their well-oriented pore distribution helps the reproducibility and homogeneity in the drug release and adsorption phases, and the high density of silanol groups enables the possibility of chemical modification of the pore walls, allowing better control over drug release and loading. The appropriate organic functionalization can increase the effective control of the drug release and drug loading. Using organic groups for promoting attractive host-guest interaction with functional groups of guest molecule would represent the drug release. It was previously shown that some mesoporous materials can provide the potential for control over the release pattern of the guest drug. ${ }^{20-24}$ For example, SBA-15 can be used for controlled release of gentamicin and amoxicillin ${ }^{25,26}$ and MCM-41 can be used for controlled release of ibuprofen. ${ }^{27-29}$

The aim of this work was to synthesize tris(2aminoethyl) amine-functionalized mesoporous silica SBA-15 and evaluate its use as citalopram delivery carrier. This paper describes the loading and release profiles of citalopram using amino polydentate SBA-15 carrier.

\section{Materials and Methods \\ Reagents \\ Poly (ethylene glycol)-block-poly (propylene glycol)- block-poly (ethylene glycol) (P123, Aldrich), tetraethyl orthosilicate (TEOS, Merck) as the source for silica, 3-chloropropyltrimethoxysilane (CPTES), tris(2- aminoethyl)-amine (Tren), toluene and ethanol (all of Merck) were used as received from suppliers. All the reagents were of analytical grade and used as received without further purification. The stock solution of citalopram (Figure 1) was prepared by dissolving its powder in double distilled water (DDW). The stock solution was diluted to prepare the desired concentration of citalopram solutions. The SBF (1000 mL) was prepared by dissolving the following chemicals in distilled water: $\mathrm{NaCl}$ (7.996 g), $\mathrm{KCl}(0.224 \mathrm{~g}), \mathrm{MgCl}_{2} .6 \mathrm{H}_{2} \mathrm{O}(0.305 \mathrm{~g}), \mathrm{CaCl}_{2}(0.278 \mathrm{~g}), 1 \mathrm{M}$ $\mathrm{HCl}(40 \mathrm{ml}), \mathrm{NaHCO}_{3}(0.350 \mathrm{~g}), \mathrm{K}_{2} \mathrm{HPO}_{4} .3 \mathrm{H}_{2} \mathrm{O}(0.228 \mathrm{~g})$, $\mathrm{Na}_{2} \mathrm{SO}_{4}(0.071 \mathrm{~g})$, and $\mathrm{NH}_{2} \mathrm{C}\left(\mathrm{CH}_{2} \mathrm{OH}\right)_{3}(6.057 \mathrm{~g})$. DDW was used in the research. The used glassware was soaked}

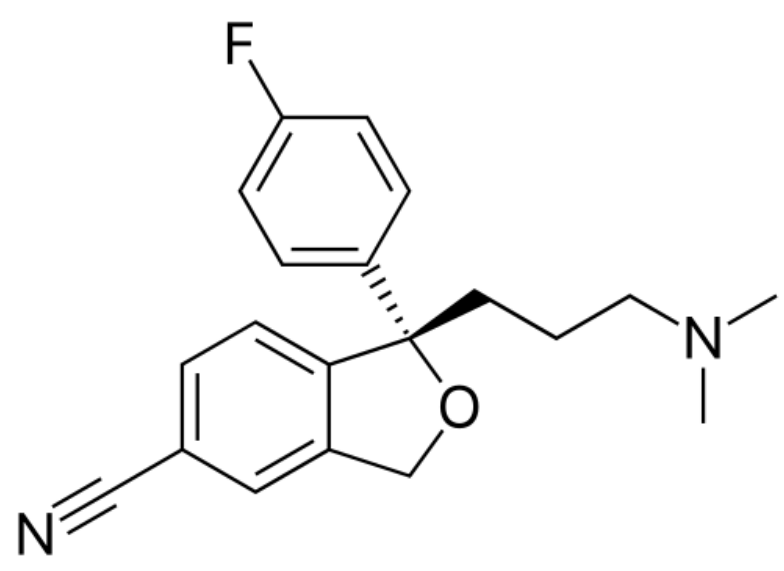

Figure 1. Molecular Structure of Citalopram.

in dilute nitric acid for about 12 hours and finally washed three times with DDW prior to use.

\section{Apparatus}

The prepared samples were characterized by powder X-ray diffraction (Philips X'pert MPD) using $\mathrm{Cu} \mathrm{Ka}$ radiation $(40 \mathrm{kV}, 30 \mathrm{~mA})$ over the range of $2 \mathrm{q}=0.5-8$. The morphology was obtained by electron scanning microscopy using an electron microscope (LEO 1455VP). Thermogravimetric analysis (TGA) measurements were performed on TA TGA Q50 at a temperature range of ambient to $900^{\circ} \mathrm{C}$. The ramp rate used was $20^{\circ} \mathrm{C} / \mathrm{min}$. $\mathrm{N}_{2}$ adsorption-desorption isotherms were measured at $-196^{\circ} \mathrm{C}$ by BELsorp-mini II. The specific surface area was estimated using the Brunauer-Emmett-Teller (BET) method, and for the pore size distribution, Barrett-JoynerHalenda (BJH) method was used. Fourier transform infrared spectra (FT-IR) were provided in a range of 600$4000 \mathrm{~cm}^{-1}$ on a Bruker Vector 22 spectrophotometer. The $\mathrm{pH}$ was controlled by Metrohm $\mathrm{pH}$-meter (model 713) and Varian UV/Vis spectrophotometer (Cary-100) was used for the measurement of citalopram concentration in the solution.

Synthesis of Tris(2-aminoethyl)amine Functionalized SBA-15

The synthesis of modified SBA-15 was carried out according to the previously reported procedure. ${ }^{30}$ First, SBA-15 was synthesized using Pluronic P123 as a structuredirecting agent and tetraethyl orthosilicate. Then, it was functionalized with CPTES to prepare Cl-SBA- 15 . Then, refluxing Cl-SBA-15 with tris(2-aminoethyl)amine (Tren) in toluene and soxhlet extraction in ethanol gave the product named as Tren-SBA-15. The detailed procedure was reported in our previous report. ${ }^{30}$

Loading and Release Study

The loading of citalopram was achieved by soaking 0.1 
$\mathrm{g}$ of the functionalized SBA-15 in $100 \mathrm{~mL}$ of saturated citalopram solution and stirring for 10 minutes at room temperature. The produced solid was filtered, washed and dried at room temperature. After drug loading, $30 \mathrm{mg}$ of the sample was weighed and put into $25 \mathrm{~mL}$ simulated body fluid (SBF) or phosphate buffers at various $\mathrm{pH}$ values. The release of citalopram was measured at time intervals by UV-Vis spectrophotometer.

\section{Results}

Characterization

The modification of SBA-15 with tris(2-aminoethyl) amine was illustrated in Figure 2.

To study the crystal structure of the products, their low-angle X-ray powder diffraction (XRD) patterns were used (Figure 3). As can be seen, SBA-15 pattern showed the (100), (110), and (200) reflection peaks which are

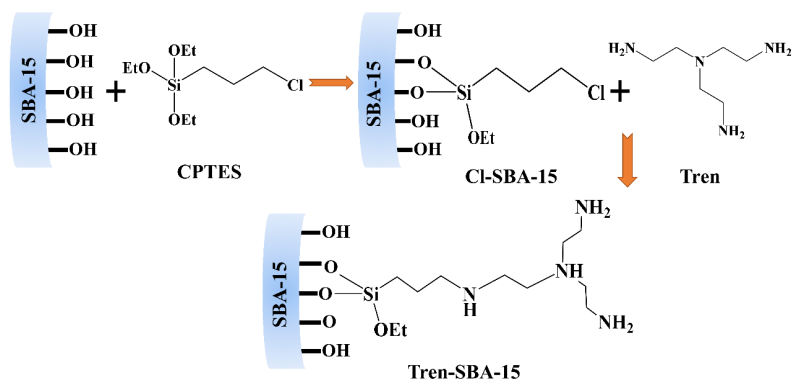

Figure 2. Schematic Display of the Functionalization of SBA-15 with CPTES and Tren.

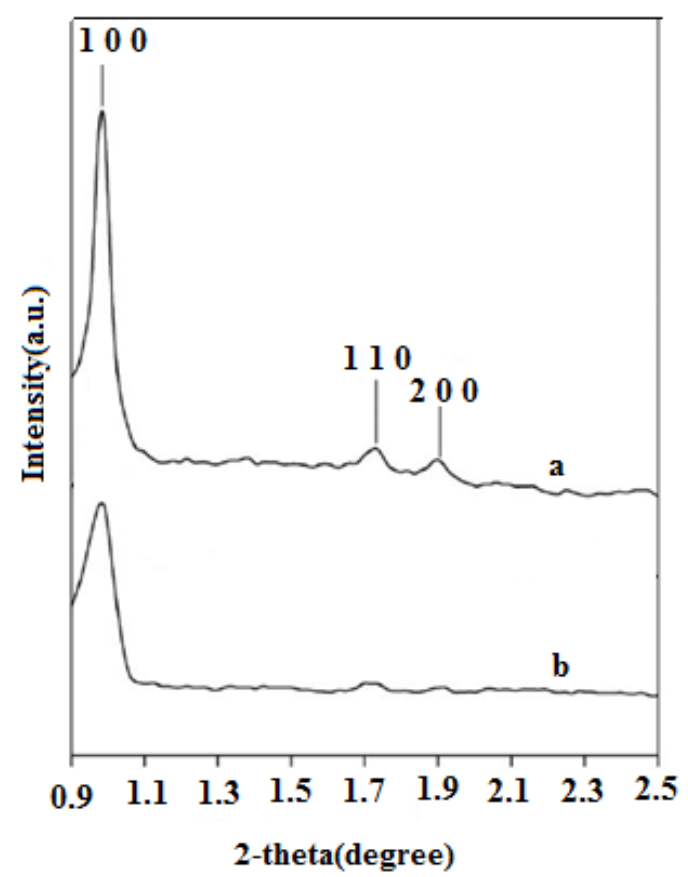

Figure 3. Low Angle XRD Patterns of (a) SBA-15, (b) Tren-SBA-15. characteristic of an ordered mesoporous silica structure with two dimensional hexagonal nanochannels. These reflections were repeated for Tren-SBA-15, implying that none of the functionalization procedures changed the structure of SBA-15. The only difference between the patterns was the decrease of the intensity of (100) diffraction peak during the modification which is ascribed to the decrease of the scattering power of the silica wall. On the other hand, this reflection was widened which might be due to narrowing the silica pores which must occur during the functionalization. Hence, the reflection (100) was attributed to the silica wall, and pore narrowing would make its reflection shift to the higher angles very slightly.

To investigate the morphology of the samples, SEM images were provided. As can be observed from Figure 4, SBA-15 consisted of some rope-like domains with a length of $1 \mu \mathrm{m}$.

The properties of the samples were characterized by N2 absorption-desorption isotherms, FTIR spectra, and TGA data and the obtained results are available in Figure 5. It is worth mentioning that the applied techniques were studied in our previous report. ${ }^{30}$

To study the textural structure of the prepared samples, N2 adsorption-desorption analysis was carried out. All the materials showed type IV isotherms with hysteresis loops attributed to mesoporous materials (Figure 5A) which indicated the maintenance of the SBA-15 structure after modifications. Besides, Figure 5A (inset) shows the pore size distributions which display a narrow pore size within the range of 2 to $8 \mathrm{~nm}$ for all the samples. Based on the textural properties which are listed in Table 1, total pore volume, lower surface area, pore size, and higher thickness of wall for the functionalized SBA-15 confirm successful modification inside the nanochannels in silica.

The FTIR spectra (Figure 5B) confirm the functional

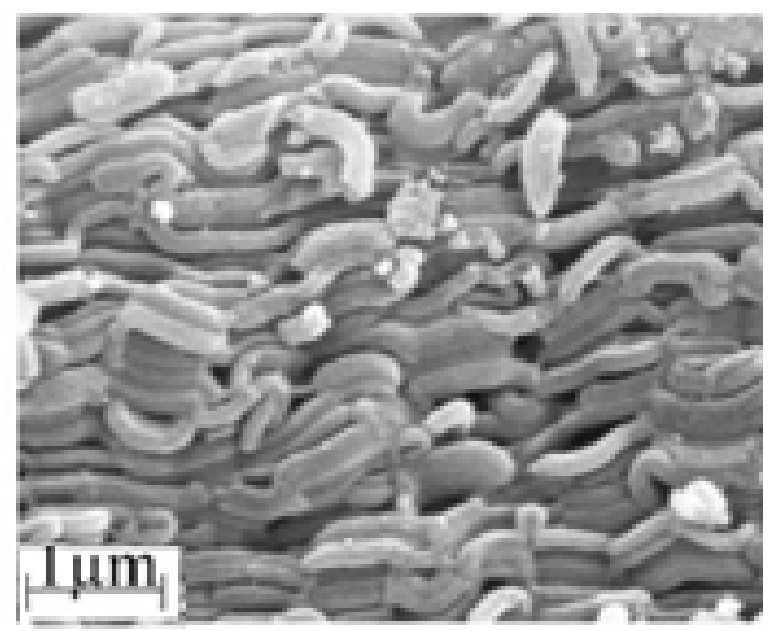

Figure 4. SEM Image of SBA-15. 


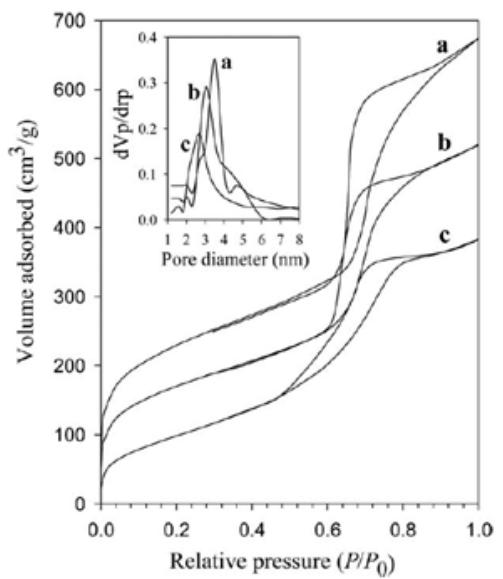

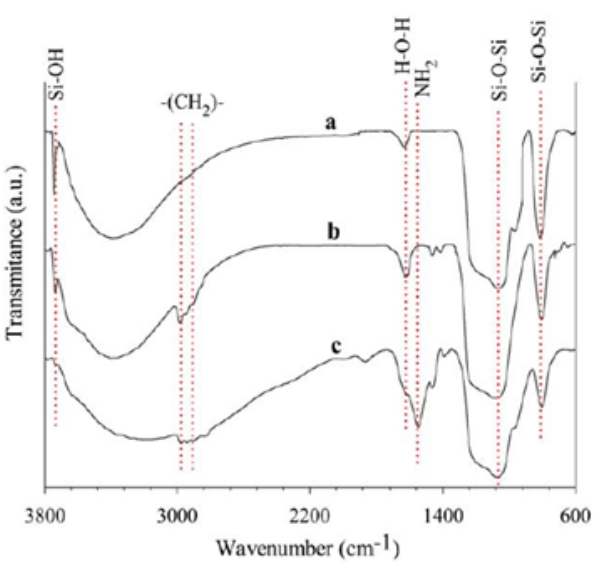

$\mathrm{C}$

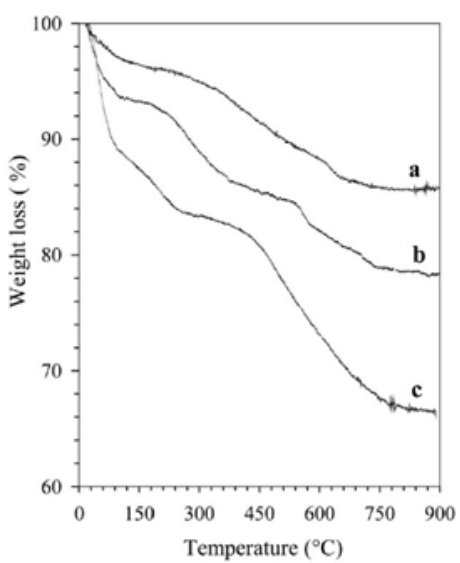

Figure 5. A: N2 Adsorption-desorption Isotherms and inset Pore Size Distribution, B: FT-IR Spectra and C: Thermogravimetric Curves of a) SBA-15, b) CI-SBA-15, c) Tren-SBA-15.

Table 1. Textural Properties of SBA-15, Cl-SBA-15, and Tren-SBA-15

\begin{tabular}{lcccc}
\hline Sample & $\begin{array}{c}\text { BET Surface } \\
\text { Area }\left(\mathbf{m}^{2} \mathbf{g}^{-1}\right)\end{array}$ & $\begin{array}{c}\text { Total Pore } \\
\text { Volume }\left(\mathbf{c m}^{\mathbf{3}} \mathbf{g}^{-1}\right)\end{array}$ & Pore size $(\mathbf{n m})$ & $\begin{array}{c}\text { Wall Thickness } \\
(\mathbf{n m})\end{array}$ \\
\hline SBA-15 & 781 & 1.5 & 7.0 & 6.0 \\
CI-SBA-15 & 581 & 1.4 & 5.4 & 7.2 \\
Tren-SBA-15 & 490 & 1.0 & 4.0 & 8.0 \\
\hline
\end{tabular}

groups created on the surface of SBA-15 after modification. The characteristic peaks of silica surface at around 1068, 811, 3392, and $3745 \mathrm{~cm}^{-1}$ attributed to the asymmetric and symmetric stretching of $\mathrm{Si}-\mathrm{O}-\mathrm{Si}$, the terminal silanol groups, and $\mathrm{OH}$ stretching vibration of $\mathrm{SiO}-\mathrm{H}$ and adsorbed $\mathrm{H}_{2} \mathrm{O}$, respectively, were shown in all the samples, except for $3745 \mathrm{~cm}^{-1}$ in Tren-SBA-15 which might be due to the hydrogen bonding occurred between $\mathrm{NH}_{2}$ group and $\mathrm{Si}-\mathrm{OH}$, or enhancing $\mathrm{H}_{2} \mathrm{O}$ adsorbed due to its hydrophilic nature. The latter suggestion was proved by the TGA that showed a higher amount of the adsorbed $\mathrm{H}_{2} \mathrm{O}$ in Tren-SBA- 15 compared to SBA-15 and Cl-SBA-15 (Figure 5C). The peaks located at 1382 and $1465 \mathrm{~cm}^{-1}$ allocated to the bending vibrations of $-\mathrm{CH}_{2}$, and 2908 and $2971 \mathrm{~cm}^{-1}$ corresponding to $\mathrm{C}-\mathrm{H}$ stretching vibrations of methylene group (Figure 5B, b and c) indicated successful anchoring of the ligands on SBA-15. Furthermore, the absorption band at $1548 \mathrm{~cm}^{-1}$ was attributed to the $\mathrm{N}-\mathrm{H}$ bending vibrations in Tren-SBA-15. As a result, FT-IR proved well the successful functionalization of the silica surface.

To estimate the amount of ligand loading on SBA-15, TGA analysis was performed (Figure 5C). The weight loss before $120^{\circ} \mathrm{C}$ which occurred in each curve was probably due to the evaporation of the adsorbed water. As can be seen, this weight loss for Tren-SBA-15 was 1.8 times higher than that for Cl-SBA-15, implying that the hydrophilic nature of amine groups on Tren-SBA-15 led to more adsorbed water. After this weight loss, another one occurred at around $500^{\circ} \mathrm{C}$ for $\mathrm{Cl}-\mathrm{SBA}-15$ and at $400^{\circ} \mathrm{C}$ for Tren-SBA-15, indicating a bit more thermal stability of chloropropyl groups in comparison to amine groups. In thermogravimetric curves of both Cl-SBA-15 and Tren-SBA-15, some weight losses happened between 120 and $800^{\circ} \mathrm{C}$, which might be attributed to gradual dehydroxylation of silica matrix. To correct this weight loss, the weight loss in this range for SBA-15 was applied as a baseline for dehydroxylating the silica. Based on these results, the loading amount of chloropropyl and Tren on SBA-15 was estimated as $1.48 \mathrm{mmol} \mathrm{g}^{-1}$ and $0.95 \mathrm{mmol} \mathrm{g}^{-1}$, respectively, implying that around $84 \%$ of chloropropyl groups on the silica surface participated in the reaction with Tren.

Measurement of the Loading of the Citalopram on Tris(2aminoethyl)-amine Functionalized SBA-15

Loading citalopram on tris(2-aminoethyl) aminefunctionalized SBA-15 was investigated by soaking of 20 and $30 \mathrm{mg}$ of functionalized SBA-15 in $10 \mathrm{~mL}$ of 10 and $15 \mathrm{mg} \mathrm{L}^{-1}$ citalopram solution and agitated for 10 minutes at room temperature. The amount of citalopram was obtained by UV-Vis spectrophotometry method. The results showed that the in all of the solutions, the concentration of citalopram decreased after contact with modified SBA-15 and it can confirm that citalopram has been incorporated into the SBA-15 molecular sieves. Moreover, the percentage of loading of citalopram on functionalized SBA-15 increased with the increase in functionalized SBA-15 quantity and citalopram concentration. Hence, the loading of citalopram was achieved by soaking of $0.1 \mathrm{~g}$ of the functionalized SBA-15 in $100 \mathrm{~mL}$ of saturated citalopram solution. The loading of citalopram on Tren-SBA-15 can be based on hydrogen bonding between the amine groups of the Tren-SBA-15 and citalopram which allows the drug to be held within the pores of functionalized SBA-15. 
The Impact of the $\mathrm{pH}$ on the Loading and Release of Citalopram

The loading of citalopram on Tren-SBA-15 was studied in various $\mathrm{pH}$ values. The $\mathrm{pH}$ of citalopram solutions was adjusted to the $\mathrm{pH}$ range of 2.0-9.0 (utilizing $1 \mathrm{~mol} \mathrm{~L}^{-1}$ of either sodium hydroxide solution or nitric acid) and the loading of citalopram was achieved by soaking $30 \mathrm{mg}$ of the Tren-SBA- 15 in $20 \mathrm{~mL}$ of $10 \mathrm{mg} \mathrm{L}^{-1}$ citalopram solution and stirring for 10 minutes at room temperature. The contents of citalopram were measured by spectrophotometry method. The percentages of citalopram adsorbed on Tren-SBA- 15 were $0 \%, 24 \%, 34 \%, 37 \%, 40 \%$, and $42 \%$ at $\mathrm{pH} 2,4,6,7,8$, and 9, respectively. The results showed that at lower $\mathrm{pH}$ values, the adsorption amount of citalopram on the functionalized SBA-15 decreased. At lower $\mathrm{pH}$ values, amino group of the functionalized SBA15 and citalopram could be protonated and therefore, the interaction between the citalopram and the Tren-SBA-15 was weaker compared to higher $\mathrm{pH}$ values.

The release profile of citalopram (percentage of drug released over time) was monitored in a stirred solution of phosphate buffers with various $\mathrm{pH}$ values. The release profiles in three different $\mathrm{pH}$ values of 5,7 , and 8 were shown in Figure 6. A faster release rate at $\mathrm{pH}=5$ (lower $\mathrm{pH}$ ), suggested a weaker interaction because of the protonation of the amino group of the functionalized SBA-15.

\section{Release of Citalopram in SBF}

The release profile of citalopram in SBF was monitored with putting $30 \mathrm{mg}$ Tren-SBA-15 into $25 \mathrm{~mL}$ SBF. The release of citalopram was measured at time intervals by $\mathrm{UV}$-Vis spectrophotometer at $\lambda=238 \mathrm{~nm}$. The results (Figure 7) showed that the rate of citalopram release from each gram of Tren-SBA-15 was $12 \mu \mathrm{g} \mathrm{h}^{-1}$, which is a slow release pattern.

\section{Discussion}

Ordered mesoporous silica with high pore volume, well-ordered pore distribution, good biocompatibility and suitable functionalization and size of mesopores are encouraging materials for controlled drug delivery systems. Drug loading and delivery rate can be changed by surface functionalization with different groups. ${ }^{31}$ This functionalization is able to alter hydrophobic/hydrophilic and electrostatic forces and the drug-matrix interactions. Therefore, we decided to introduce a method for the delivery of citalopram by functionalized mesoporous molecular sieve to improve the medical impact of citalopram. Loading citalopram was achieved by soaking of the tris(2-aminoethyl) amine-functionalized SBA15 in saturated citalopram solution. Afterwards, the release of citalopram in SBF and phosphate buffers was measured. It should be noticed that functionalized SBA-15 was used in our work because it is well known

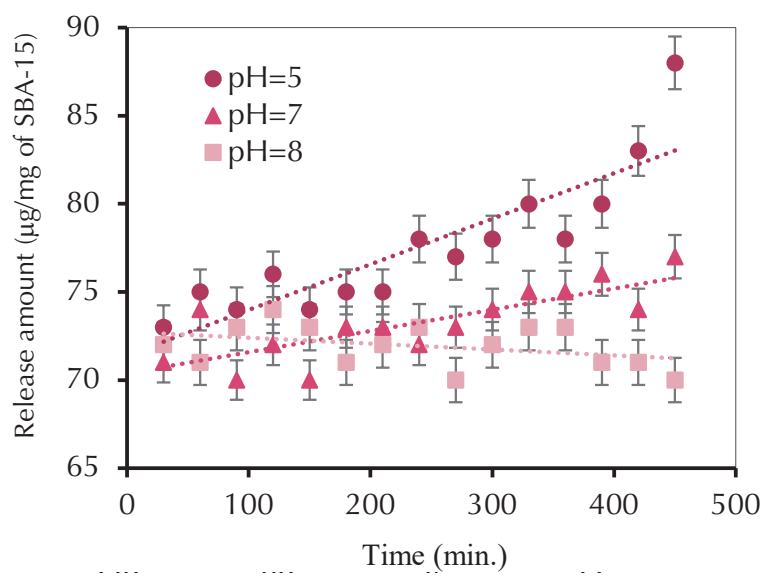

Figure 6. Citalopram Release Profile in Phosphate Buffers.

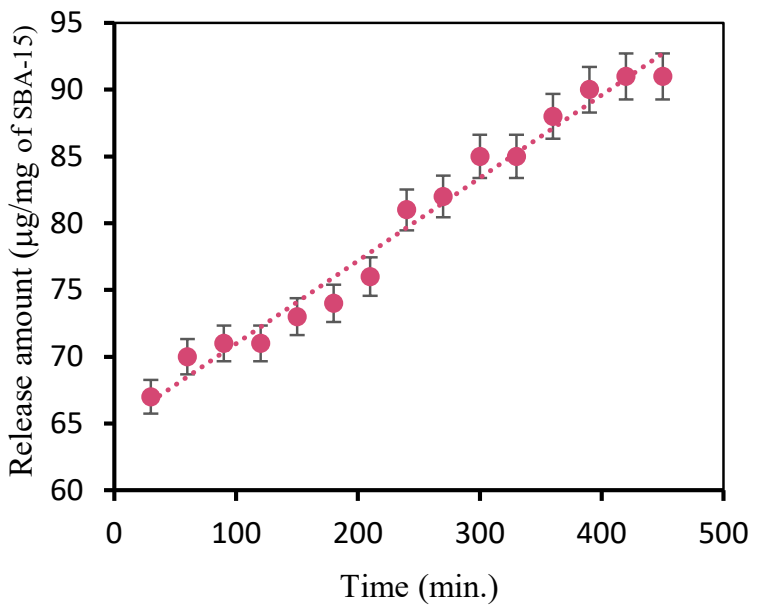

Figure 7. Citalopram Release Profile in a Simulated Body Fluid.

that the rate of drug release from the functionalized mesoporous materials is effectively controlled as compared to that from pure mesoporous materials. For example, two MCM-41 materials with various pore sizes were modified with aminopropyl group ${ }^{32}$ for controlling the ibuprofen delivery rate. The results have shown that the functionalizing process was effective in both drug adsorption and drug release profile as functionalized MCM-41 released ibuprofen in a slower delivery rate. Moreover, Zeng et $\mathrm{al}^{33}$ performed a similar study on controlled delivery of aspirin using MCM-41 substances modified by organic aminopropyl groups. It has been observed that the amount of aminopropyl groups on the ordered structure and the pore wall of mesoporous substances influence the releasing features of this delivery system. Additionally, Prokopowicz et $\mathrm{al}^{34}$ studied the SBA-15 and rehydroxylated SBA-15 (SBA-15-R) as the bioactive drug delivery system using doxorubicin. The assays were carried out in vitro. For the SBA-15, the total drug release at $\mathrm{pH}=7.4$ was found after 144 hours, whereas for SBA-15-R, it was found after 170 hours. A comparison 
of calcined SBA-15 and the functionalized SBA-15 with long alkyl chains like octadecyltrimethoxysilane and octyltrimethoxysilane in controlled delivery patterns was done by Doadrio et al. ${ }^{24}$ The mesoporous samples were charged with the macrolide antibiotic erythromycin and the release assays were performed in vitro. The results showed that by increasing the number of hydrophobic$\mathrm{CH}_{2}$ moieties in the host, the release rate decreased.

The low angle XRD patterns of SBA-15 and Tren-SBA-15 showed an ordered mesoporous silica structure with twodimensional hexagonal nanochannels and established that the functionalization did not change the structure of Tren-SBA-15. Similar to previous reports, ${ }^{35}$ SEM images showed that SBA-15 consisted of some rope-like domains with a length of $1 \mu \mathrm{m}$. The textural properties which were extracted from $\mathrm{N}_{2}$ adsorption-desorption analysis were listed in Table 1, displaying lower total pore volume, surface area, and pore size and higher wall thickness for the functionalized SBA-15 which confirm successful modification inside the nanochannels in silica. ${ }^{36}$ In addition, FT-IR proved the successful functionalization of the silica surface and anchoring of the ligands on SBA$15 .^{37,38}$ Based on TGA analysis, the loading amount of chloropropyl and Tren on SBA-15 was estimated as 1.48 mmol g ${ }^{-1}$ and $0.95 \mathrm{mmol} \mathrm{g}^{-1}$, respectively, implying that around $84 \%$ of chloropropyl groups on the silica surface participated in the reaction with Tren.

The results showed that at lower $\mathrm{pH}$ values, the loading percentage of citalopram on the functionalized SBA-15 decreased. The loading percentage was $42 \%$ at $\mathrm{pH}=9$ and $24 \%$ at $\mathrm{pH}=4$. At lower $\mathrm{pH}$ values, the amino group of the functionalized SBA-15 and citalopram could be protonated and therefore, the interaction between the citalopram and the Tren-SBA-15 was weaker compared to higher $\mathrm{pH}$ values. Similar results were reported by ValletRegi et al. ${ }^{23}$ They examined the calcined SBA-15 material for the delivery of amoxicillin. It was observed that the amount of drug loaded into the SBA-15 porous matrix greatly relied on the $\mathrm{pH}$ value.

This study revealed that the release rate of citalopram depends on $\mathrm{pH}$ value. The release profiles at the three different $\mathrm{pH}$ values of 5, 7, and 8 (Figure 5) showed a faster release rate at $\mathrm{pH}=5$ (lower $\mathrm{pH}$ ), suggesting a weaker interaction because of the protonation of the amino group of the functionalized SBA-15. Li et al ${ }^{39}$ reported similar results. They demonstrated the feasibility of controlling the delivery rate of ibuprofen occluded in two multifunctional amine mesoporous silica spheres. They showed $\mathrm{pH}$ responsive control for drug release. They showed that amine-functionalized mesoporous silica spheres have a faster release rate at low $\mathrm{pH}$ values (4.5) than at higher $\mathrm{pH}$ values (7.45). Moreover, Prokopowicz et $\mathrm{al}^{34}$ indicated that the drug release profile of rehydroxylated SBA-15 was $\mathrm{pH}$-dependent. In comparison with phosphate buffer $(\mathrm{pH}=5.0)$, drug release in $\mathrm{SBF}(\mathrm{pH}=7.4)$ was slower, mostly because of stronger electrostatic interactions and simultaneous deposition of phosphate and calcium ions onto the silica surface.

Finally, the release profile of citalopram in SBF was monitored. The results (Figure 6) showed that the rate of citalopram release from each gram of Tren-SBA-15 was 12 $\mu \mathrm{g} \mathrm{h}{ }^{-1}$. The results demonstrated that the release process was very slow and had a relatively constant rate over the subsequent hours.

\section{Conclusion}

This paper describes a method for the delivery of citalopram by Tren-SBA-15 molecular sieve in order to improve the medical effect of citalopram. The method is based on the interaction between amine groups in citalopram and Tren-SBA-15. The results showed that the loading amount and release rate of the drug depended on $\mathrm{pH}$ value. Additionally, a very slow release pattern was observed. Therefore, the Tren-SBA-15 is a suitable carrier for encapsulating citalopram molecules through its ordered functionalized nanopores and for controlled release of it.

\section{Conflict of Interest Disclosure}

There were no competing interests in this study.

\section{Authors' Contribution}

FD: Data collection, Data analysis.

LH: The conception and design of the study, Supervision, Conducting experiments, Literature search, Data analysis, Manuscript writing/editing.

AB: Conducting experiments, Literature search, Data analysis, Manuscript writing/editing.

EBA: Data collection, Data analysis.

MRG: Data analysis, Manuscript editing.

GMZ: Literature search, Data analysis.

\section{Acknowledgment}

The authors would like to thank the Research Council of Islamic Azad University of Yadegar-e-Imam Khomeini (RAH), Shahre Rey, for supporting this work.

\section{References}

1. Hesketh SA, Brennan AK, Jessop DS, Finn DP. Effects of chronic treatment with citalopram on cannabinoid and opioid receptor-mediated G-protein coupling in discrete rat brain regions. Psychopharmacology (Berl). 2008;198(1):29-36. doi:10.1007/s00213-007-1033-3

2. Celexa (citalopram hydrobromide) Tablets/Oral Solution. Prescribing Information. Forest Laboratories, Inc. https://www.accessdata.fda.gov/drugsatfda_docs/ label/2012/020822s043lbl.pdf.

3. Nemeroff CB. Management of Treatment-Resistant Major Psychiatric Disorders. New York: Oxford University Press; 2012.

4. Urząd Rejestracji Produktów Leczniczych, Wyrobów 
Medycznych i Produktów Biobójczych (Office for Registration of Medicinal Products, Medical Devices and Biocides). http://www.urpl.gov.pl/system/drugs/ dcp/charakterystyka/2012-07-02_2012-04-20-spccitalopramvb-pl.pdf.

5. British National Formulary: BNF 76. 76th ed. Pharmaceutical Press; 2018.

6. Perna G, Bertani A, Caldirola D, Smeraldi E, Bellodi L. A comparison of citalopram and paroxetine in the treatment of panic disorder: a randomized, singleblind study. Pharmacopsychiatry. 2001;34(3):85-90. doi:10.1055/s-2001-14283

7. Stahl SM. Prescriber's Guide: Stahl's Essential Psychopharmacology. New York: Cambridge University Press; 2011.

8. Abnormal heart rhythms associated with high doses of Celexa (citalopram hydrobromide). Safety Communication. United States Food and Drug Administration; 24 August 2011.

9. Personne M, Sjöberg G, Persson H. Citalopram overdose--review of cases treated in Swedish hospitals. J Toxicol Clin Toxicol. 1997;35(3):237-240. doi:10.3109/15563659709001206

10. Luchini D, Morabito G, Centini F. Case report of a fatal intoxication by citalopram. Am J Forensic Med Pathol. 2005;26(4):352-354. doi:10.1097/01.paf.0000188276.33030. dd

11. Taylor D, Paton C, Kapur S. The Maudsley Prescribing Guidelines in Psychiatry (Taylor, The Maudsley Prescribing Guidelines). Hoboken, USA: Wiley-Blackwell; 2012:588.

12. Beck JS, Vartuli JC, Roth WJ, et al. A new family of mesoporous molecular sieves prepared with liquid crystal templates. J Am Chem Soc. 1992;114(27):10834-10843. doi:10.1021/ja00053a020

13. Reinert P, Garcia B, Morin C, et al. Cationic tern plating with organic counterion for superstable mesoporous silica. Stud Surf Sci Catal. 2003;146:133-136. doi:10.1016/S01672991(03)80345-2

14. Bonneviot L, Morin M, Badiei A. Mesostructured Metal or Non-Metal Oxides and Method for Making Same. Patent WO 01/55031 A1, 2001.

15. Zhao D, Huo Q, Feng J, Chmelka BF, Stucky GD. Nonionic triblock and star diblock copolymer and oligomeric surfactant syntheses of highly ordered, hydrothermally stable, mesoporous silica structures. J Am Chem Soc. 1998;120(24):6024-6036. doi:10.1021/ja974025i

16. Ganjali MR, Daftari A, Hajiagha-Babaei L, et al. Pico level monitoring of silver with modified hexagonal mesoporous compound (MCM-41) and inductively coupled plasma atomic emission spectrometry. Water Air Soil Pollut. 2006;173(1):71-80. doi:10.1007/s11270-005-9027-4

17. Ganjali MR, Hajiagha-Babaei L, Badiei A, Mohammadi Ziarani G, Tarlani A. Novel method for the fast preconcentration and monitoring of a ppt level of lead and copper with a modified hexagonal mesoporous silica compound and inductively coupled plasma atomic emission spectrometry. Anal Sci. 2004;20(4):725-729. doi:10.2116/analsci.20.725

18. Anbia M, Salehi S. Removal of acid dyes from aqueous media by adsorption onto amino-functionalized nanoporous silica SBA-3. Dyes and Pigments. 2012;94(1):19. doi:10.1016/j.dyepig.2011.10.016

19. Trong On D, Desplantier-Giscard D, Danumah C, Kaliaguine S. Perspectives in catalytic applications of mesostructured materials. Appl Catal A Gen. 2001;222(12):299-357. doi:10.1016/S0926-860X(01)00842-0

20. Vallet-Regí M, Rámila A, del Real RP, Pérez-Pariente J. A new property of MCM-41: drug delivery system. Chem Mater. 2001;13(2):308-311. doi:10.1021/cm0011559

21. Horcajada P, Rámila A, Pérez-Pariente J, Vallet-Regí M. Influence of pore size of MCM-41 matrices on drug delivery rate. Microporous Mesoporous Mater. 2004;68(13):105-109. doi:10.1016/j.micromeso.2003.12.012

22. Doadrio AL, Sousa EM, Doadrio JC, Pérez Pariente J, Izquierdo-Barba I, Vallet-Regí M. Mesoporous SBA-15 HPLC evaluation for controlled gentamicin drug delivery. J Control Release. 2004;97(1):125-132. doi:10.1016/j. jconrel.2004.03.005

23. Vallet-Regí M, Doadrio JC, Doadrio AL, Izquierdo-Barba I, Pérez-Pariente J. Hexagonal ordered mesoporous material as a matrix for the controlled release of amoxicillin. Solid State Ion. 2004;172(1-4):435-439. doi:10.1016/j. ssi.2004.04.036

24. Doadrio JC, Sousa EM, Izquierdo-Barba I, Doadrio AL, Pérez-Pariente J, Vallet-Regí M. Functionalization of mesoporous materials with long alkyl chains as a strategy for controlling drug delivery pattern. Journal of Materials Chemistry. 2006;16(5):462-466. doi:10.1039/B510101H

25. Lebold T, Jung C, Michaelis J, Bräuchle C. Nanostructured silica materials as drug-delivery systems for doxorubicin: single molecule and cellular studies. Nano Lett. 2009;9(8):2877-2883. doi:10.1021/nl9011112

26. Charnay C, Bégu S, Tourné-Péteilh C, Nicole L, Lerner DA, Devoisselle JM. Inclusion of ibuprofen in mesoporous templated silica: drug loading and release property. Eur J Pharm Biopharm. 2004;57(3):533-540. doi:10.1016/j. ejpb.2003.12.007

27. Goscianska J, Olejnik A, Pietrzak R. Adsorption of 1-phenylalanine onto mesoporous silica. Mater Chem Phys. 2013;142(2-3):586-593. doi:10.1016/j. matchemphys.2013.07.057

28. Zhu S, Zhou Z, Zhang D, Jin C, Li Z. Design and synthesis of delivery system based on SBA-15 with magnetic particles formed in situ and thermo-sensitive PNIPA as controlled switch. Microporous Mesoporous Mater. 2007;106(13):56-61. doi:10.1016/j.micromeso.2007.02.027

29. Yu H, Zhai QZ. Mesoporous SBA-15 molecular sieve as a carrier for controlled release of nimodipine. Microporous Mesoporous Mater. 2009;123(1-3):298-305. doi:10.1016/j. micromeso.2009.04.013

30. Badiei A, Mirahsani A, Shahbazi A, Younesi H, Alizadeh M. Adsorptive removal of toxic dye from aqueous solution and real industrial effluent by tris (2-aminoethyl) amine functionalized nanoporous silica. Environ Prog Sustain Energy. 2014;33(4):1242-1250. doi:10.1002/ep.11923

31. Wang S. Ordered mesoporous materials for drug delivery. Microporous Mesoporous Mater. 2009;117(1-2):1-9. doi:10.1016/j.micromeso.2008.07.002

32. Muñoz B, Rámila A, Pérez-Pariente J, Díaz I, Vallet-Regí M. MCM-41 organic modification as drug delivery rate 
regulator. Chem Mater. 2003;15(2):500-503. doi:10.1021/ $\mathrm{cm} 021217 \mathrm{q}$

33. Zeng W, QianXF,Zhang YB, Yin J,ZhuZK. Organicmodified mesoporous MCM-41 through solvothermal process as drug delivery system. Mater Res Bull. 2005;40(5):766-772. doi:10.1016/j.materresbull.2005.02.011

34. Prokopowicz M, Żeglinski J, Szewczyk A, Skwira A, Walker G. Surface-activated fibre-like SBA-15 as drug carriers for bone diseases. AAPS PharmSciTech. 2018;20(1):17. doi:10.1208/s12249-018-1243-5

35. Zhao D, Feng J, Huo Q, et al. Triblock copolymer syntheses of mesoporous silica with periodic 50 to 300 angstrom pores. Science. 1998;279(5350):548-552. doi:10.1126/ science.279.5350.548

36. Badiei A, Goldooz H, Ziarani GM, Abbasi A. One pot synthesis of functionalized SBA-15 by using an 8-hydroxyquinoline-5-sulfonamide-modified organosilane as precursor. J Colloid Interface Sci. 2011;357(1):63-69. doi:10.1016/j.jcis.2011.01.049

37. Badiei A, Goldooz H, Ziarani GM. A novel method for preparation of 8-hydroxyquinoline functionalized mesoporous silica: aluminum complexes and photoluminescence studies. Appl Surf Sci. 2011;257(11):4912-4918. doi:10.1016/j.apsusc.2010.12.146

38. Benhamou A, Baudu M, Derriche Z, Basly JP. Aqueous heavy metals removal on amine-functionalized SiMCM-41 and Si-MCM-48. J Hazard Mater. 2009;171(13):1001-1008. doi:10.1016/j.jhazmat.2009.06.106

39. Li Y, Song F, Guo Y, Cheng L, Chen Q. Multifunctional amine mesoporous silica spheres modified with multiple amine as carriers for drug release. J Nanomater. 2018;2018:1726438. doi:10.1155/2018/1726438 